\title{
Evaluation of milk cathelicidin for detection of dairy sheep mastitis
}

\author{
M. F. Addis, ${ }^{* 1}$ V. Tedde, ${ }^{*}$ S. Dore, $†$ S. Pisanu, ${ }^{*}$ G. M. G. Puggioni, ${ }^{*}$ A. M. Roggio, ${ }^{*}$ D. Pagnozzi, ${ }^{*}$ S. Lollai, $\dagger$ \\ E. A. Cannas, $†$ and S. Uzzau* $\ddagger^{1}$ \\ *Porto Conte Ricerche, SP 55 Porto Conte/Capo Caccia, Loc. Tramariglio, 07041 Alghero, Italy \\ †C.Re.N.M.O.C. (Centro di Referenza Nazionale per le Mastopatie degli Ovini e dei Caprini), Istituto Zooprofilattico Sperimentale della Sardegna, \\ Via Duca degli Abruzzi 8, 07100 Sassari, Italy \\ fUniversità degli Studi di Sassari, Dipartimento di Scienze Biomediche, Viale S. Pietro 43/B, 07100 Sassari, Italy
}

\begin{abstract}
Mastitis due to intramammary infections is one of the most detrimental diseases in dairy sheep farming, representing a major cause of reduced milk productions and quality losses. In particular, subclinical mastitis presents significant detection and control problems, and the availability of tools enabling its timely, sensitive, and specific detection is therefore crucial. We have previously demonstrated that cathelicidins, small proteins implicated in the innate immune defense of the host, are specifically released in milk of mastitic animals by both epithelial cells and neutrophils. Here, we describe the development of an ELISA for milk cathelicidin and assess its value against somatic cell counts (SCC) and bacteriological culture for detection of ewe mastitis. Evaluation of the cathelicidin ELISA was carried out on 705 half-udder milk samples from 3 sheep flocks enrolled in a project for improvement of mammary health. Cathelicidin was detected in 35.3\% of milk samples (249/705), and its amount increased with rising SCC values. The cathelicidin-negative (n $=456)$ and cathelicidin-positive $(\mathrm{n}=249)$ sample groups showed a clear separation in relation to SCC, with median values of 149,500 and 3,300,000 cells/ $\mathrm{mL}$, respectively. Upon bacteriological culture, $20.6 \%$ $(145 / 705)$ of the milk samples showed microbial growth, with coagulase-negative staphylococci being by far the most frequent finding. A significant proportion of all bacteriologically positive milk samples were positive for cathelicidin $(110 / 145,75.9 \%)$. Given the lack of a reliable gold standard for defining the true disease status, sensitivity (Se) and specificity (Sp) of the cathelicidin ELISA were assessed by latent class analysis against 2 SCC thresholds and against bacteriological culture results. At an SCC threshold of 500,000 cells/mL, Se and $\mathrm{Sp}$ were 92.3 and $92.3 \%$ for cathelicidin ELISA, 89.0 and $94.9 \%$ for SCC, and 39.4 and $93.6 \%$ for bac-
\end{abstract}

\footnotetext{
Received August 20, 2015.

Accepted April 23, 2016.

${ }^{1}$ Corresponding authors: addis@portocontericerche.it and uzzau@ uniss.it
}

teriological culture, respectively. At an SCC threshold of 1,000,000 cells $/ \mathrm{mL}$, Se and Sp were 93.3 and $91.9 \%$ for cathelicidin ELISA, 80.0 and $97.1 \%$ for SCC, and 39.4 and $93.5 \%$ for bacteriology, respectively. In view of the results obtained in this study, the measurement of cathelicidin in milk by ELISA can provide added Se while maintaining a high Sp and may therefore improve detection of subclinical mastitis.

Key words: subclinical mastitis, ewe, small ruminant, ELISA

\section{INTRODUCTION}

Mastitis due to IMI is one of the major issues affecting dairy sheep worldwide and negatively affects milk production yields and quality (Bergonier et al., 2003). The difficulties in its detection and the high incidence of subclinical mastitis further exacerbate the problem. Therefore, the availability of tools enabling its timely, sensitive, and specific detection is key for ensuring productivity of the sheep farm. Adding to the clinical evaluation (Marogna et al., 2010), the most widespread approaches for monitoring and assessing flock health are milk SCC and bacteriological culture (Bergonier et al., 2003; Contreras et al., 2007). Nevertheless, both methods present drawbacks in terms of sensitivity (Se), specificity $(\mathbf{S p})$, costs, and trained personnel requirements and pose various practical or technical challenges (McDougall et al., 2001; Souza et al., 2012). The diagnostic value of SCC is based on the principle that the number of cells in milk increases when a bacterial infection occurs because of the alveolar influx of neutrophils that are recruited in the context of the inflammatory response. However, numerous noninfectious factors affect SCC, including age, breed, level of genetic selection, lactation stage, parity, milking technique, time of day, feeding, grazing style, udder shape, drought and other environmental stressors, and vaccinations or underlying viral infections (Bergonier et al., 2003; Souza et al., 2012). In addition, the type of causative agent can influence SCC in different ways, in terms of both intensity and duration. Accordingly, the single thresh- 
olds proposed in ewes range from 200,000 to 1.5 million cells $/ \mathrm{mL}$, but in most cases, values below 500,000 cells/ $\mathrm{mL}$ are indicated (Bergonier et al., 2003; Contreras et al., 2007; Souza et al., 2012). Recently, it has been suggested that SCC of $<500,000$ or $>1,000,000$ cells/ $\mathrm{mL}$ should reliably indicate the absence or presence of mastitis, respectively (Berthelot et al., 2005; Fragkou et al., 2014; Gelasakis et al., 2015), although a "gray area" remains between these threshold values with this approach. In addition, by using 500,000 cells $/ \mathrm{mL}$ as the lower threshold, a higher Se assay may be required to ensure detection of all subclinical mastitis cases.

For a bacteriological culture, a positive result should provide direct evidence that an IMI is present, with the added advantage of identifying the causative microorganism. Nevertheless, milk culturing is known to suffer Se issues due to the intermittent shedding of microorganisms in milk, failure of the microorganism to grow in the culture medium, low multiplicities of infection, and the possible presence of antibiotics due to treatment as well as that of antimicrobial molecules produced by the host immune system itself, such as lysozyme, ferritin, lactoferrin, and antimicrobial peptides (Rainard and Riollet, 2006; Walker et al., 2011; Souza et al., 2012). In addition, some mastitis agents can be more difficult to isolate in culture. Specificity issues also exist due to the possible growth of environmental or commensal bacteria. In addition, possible species or genus misassignments following biochemical identification tests need to be taken into account (Plumed-Ferrer et al., 2013). However, and most importantly in the context of Se, Sp, and practical issues, the bacteriological examination of milk has the main aim of identifying the infectious agents so the correct measures can be implemented for controlling or eliminating the disease at the flock or herd level.

Given the preceding considerations and limitations, a constant search is underway for other indicators of inflammation that would enable more efficient, sensitive, and specific detection of mastitis, to be used either as an alternative to SCC or as a supplement for assessing or improving SCC performance (Viguier et al., 2009; Gurjar et al., 2012). A feasible approach is to use the molecules that are specifically released in milk in response to a microbial infection as indicators or markers. Ideally, to maintain general mastitis screening capabilities, as with SCC, the marker should be a molecule, enzyme, or protein that is suitable for detection with enzymatic assays or immunoassay procedures and is released in milk as a result of inflammation within the mammary gland (Viguier et al., 2009). In keeping with this goal, dedicated biomarker discovery studies, carried out mainly in cows, have reported different proteins that are released in mastitic milk and might therefore have potential for IMI detection (Boehmer et al., 2010; Akerstedt et al., 2011; Ceciliani et al., 2012; Wheeler et al., 2012). Recent studies in sheep by our group have revealed that cathelicidins are among the most prominent and promising molecules for this purpose because they are released abundantly, specifically, and very early in milk following a microbial stimulus. In our studies, their significant and specific increase was seen in milk and in mammary tissues upon natural infection of sheep by Mycoplasma agalactiae as well as following experimental infection by Streptococcus uberis (Addis et al., 2011, 2013). Indications of cathelicidin release upon IMI have also been provided by other authors in cows (Murakami et al., 2005; Ibeagha-Awemu et al., 2010; Smolenski et al., 2011) and in goats (Brenaut et al., 2014).

Cathelicidins are a family of innate immune effectors that possess multiple functions, including direct antimicrobial activity and potent chemotactic and proinflammatory functions (Zanetti, 2004, 2005; Wiesner and Vilcinskas, 2010). Eight genes are known in sheep (Kościuczuk et al., 2012), and 4 have been demonstrated to be expressed in milk during an inflammatory response, including cathelicidin-1, -2 , and -3 (Addis et al., 2013; Scumaci et al., 2015; Pisanu et al., 2015) and the cathelicidin-derived myeloid antimicrobial peptide (Addis et al., 2011). Milk leukocytes contain cathelicidin as the main component of the neutrophil secondary granules, accounting for about $4 \%$ of the total protein content (Zanetti et al., 1991). In these cells, the protein is stored preformed, and it is quickly and massively released on demand following a microbial stimulus, often even before the onset of clinical symptoms (Smolenski et al., 2011; Addis et al., 2013). In addition, cathelicidin is strongly associated with the neutrophil extracellular traps released in milk upon IMI (Lippolis et al., 2006; Reinhardt et al., 2013; Pisanu et al., 2015).

Notably, mammary epithelial cells also release cathelicidin and other antimicrobial proteins as one of the first events triggered by the entry of pathogens in the udder, in a rapid, sensitive, and specific manner (Addis et al., 2011, 2013). Cathelicidin release therefore occurs synergistically both in epithelial cells and in milk neutrophils, providing the first line of defense against the microbial invader by acting as a direct antimicrobial agent as well as a potent chemoattractant and proinflammatory mediator (Zanetti, 2004, 2005; Chromek et al., 2006; Nijnik and Hancock, 2009). Following this initial response, a massive influx of immune cells is recalled in the udder, with further degranulation and peaking of cathelicidin in milk (Addis et al., 2013). Therefore, the production of cathelicidin by epithelial cells as a sentinel act in response to microbial invasion makes these proteins even more relevant as early 
and sensitive markers of an infectious event. Further advantages of cathelicidin compared with several other inflammation markers are that it is almost undetectable in the milk of healthy animals, unlike other antimicrobial proteins, and its levels increase quickly and significantly only upon exposure to an inflammatory stimulus. Moreover, if an infection is not established, cathelicidin levels rapidly return to baseline, and the same is thought to occur in late and resolving infections (Saad and Ostensson, 1990; Sladek et al., 2005; Smolenski et al., 2011). All these factors, combined with its proteinaceous nature and molecular dimensions, make cathelicidin a perfectly suitable target for the development of different immunoassay formats for diagnostic uses.

Based on these premises, the purpose of this study was to investigate the value of milk cathelicidin for improving Se and Sp of mastitis detection in ewes and to investigate its correlations with SCC and bacteriological culture. For these purposes, we implemented ELISA, one of the most standardized and widespread immunoassay platforms, for the detection of cathelicidin. In this article, we report the results obtained and present a critical discussion of them.

\section{MATERIALS AND METHODS}

\section{Flocks}

A total of 705 milk samples were collected in 2014 and 2015 from half-udders of Sarda ewes in full lactation belonging to 3 different semi-intensive dairy flocks (A, B, and C) located in northwestern Sardinia (Italy) and certified by the Istituto Zooprofilattico Sperimentale as being Mycoplasma agalactiae-free. Milk sampling occurred in the context of a project for improvement of sheep mammary health and reduction of CNS mastitis. Specifically, flock A was sampled once, for a total of 133 sheep. Flock B was sampled 3 times, once in 2014, for a total of 136 sheep, and twice in 2015, for a total of 299 sheep (113 and 186, respectively). Flock C was sampled twice in 2015, for a total of 137 sheep (54 and 83, respectively).

\section{Milk Sampling}

Before sampling, teat ends were carefully cleaned and disinfected with a commercial postmilking teat disinfectant with the following formulation: $0.5 \%$ chlorhexidine digluconate, $4.0 \%$ isopropyl alcohol, $4.0 \%$ glycerin, and $0.5 \%$ ethoxylated lanolin. The first streams of foremilk were discarded, and then approximately $40 \mathrm{~mL}$ of milk was collected aseptically from each teat into sterile 50$\mathrm{mL}$ graduated test tubes. Milk samples were stored at
$4 \pm 2^{\circ} \mathrm{C}$ and analyzed for SCC and bacterial culture within $12 \mathrm{~h}$ at the National Reference Laboratory for Sheep and Goat Mastopathy.

\section{Somatic Cell Content Determination}

Somatic cell counts were determined by the fluoroopto-electronic method with a Fossomatic FC instrument (Foss Electric, Hillerød, Denmark) according to ISO (2006).

\section{Bacteriological Culture}

Milk samples were cultured following standard procedures (Watts, 1990). Ten microliters of milk was streaked onto the surface of $5 \%$ sheep blood agar plates. Plates were incubated at $37^{\circ} \mathrm{C}$ under aerobic conditions and examined for growth after 24 and $48 \mathrm{~h}$. The isolation of 3 or more types of colony was considered to result from contamination. Preliminary characterization of isolates included colony morphology, hemolytic activity, and Gram staining (Gram stain kit, Becton-Dickinson Co., Franklin Lakes, NJ). Gram-positive cocci were screened for catalase activity. Suspected staphylococci were then identified by means of coagulase test (Coagulase Plasma Rabbit with EDTA, BD), production of clumping factor (Staphylase Test, Oxoid, Basingstoke, UK), and biochemical strips (API Staph, bioMérieux, Marcy l'Etoile, France). Gram-positive cocci with no or weak catalase production were identified by means of API 20 Strep (bioMérieux). Gram-negative bacteria were tested for oxidase production (Bactident Oxidase, Merck, Darmstadt, Germany) and then identified by API 20 E or API 20 NE (bioMérieux). All commercial tests were performed according to the manufacturers' instructions.

\section{Pan-Cathelicidin ELISA}

The pan-cathelicidin peptide (PCP) sequence used to develop the pan-cathelicidin ELISA included a region having identities of $100 \%$ with CTHL1_SHEEP, $72 \%$ with CHTL2_SHEEP, $70 \%$ with CTHL3_SHEEP, $81 \%$ with SC51_SHEEP, and 80\% with SC52_SHEEP, respectively. All the sequences were retrieved from the nonredundant UniProtKB/SwissProt Database (http://www.uniprot.org/). The PCP was synthesized according to the solid-phase procedure of Merrifield (1963) using a microwave single-mode Discover SPS reactor insert in a peptide synthesizer Liberty (CEM Corporation, Matthews, NC) by fluorenylmethyloxycarbonyl chloride (Fmoc)-based solid-phase peptide synthesis. All Fmoc amino acids were obtained from Novabiochem (Laufelfingen, Switzerland). The crude peptide was purified by reverse-phase HPLC on an HP 
1200 (Agilent Technologies, Santa Clara, CA) instrument connected to a UV-Vis detector, as described previously (Mura et al., 2011). The purified peptide mixture was analyzed and characterized on a quadrupole time-of-flight hybrid mass spectrometer equipped with a nano Z-spray source (Waters, Manchester, UK), as described previously (Maddau et al., 2009), after direct injection of the peptide solution into the ion source.

Anti-PCP monoclonal antibodies were obtained from Abbiotec (San Diego, CA) by using PCP as the antigen. The 2 best performing monoclonal antibodies were chosen among the 11 available clones by Western immunoblotting against PCP and against a panel of mastitic milk samples, according to standard procedures (Addis et al., 2011). Milk ELISA for pan-cathelicidin detection was developed in house according to standard procedures (Danowski et al., 2013; Miglio et al., 2013; Trend et al., 2015) in a sandwich format. The detection antibody was conjugated with horseradish peroxidase using a commercial kit (Lightning-Link, Horseradish Peroxidase, Innova Biosciences Ltd., Cambridge, UK). Six bacteriologically negative milk samples with less than 150,000 cells/mL were included in all ELISA plates and used for absorbance normalization. Normalization was done by subtracting from each optical density (OD) value measured in the plate, the average $\mathrm{OD}_{450}+3 \mathrm{SD}$ of the 6 samples measured in the same plate.

\section{Statistics}

According to the Shapiro-Wilk normality test, the data followed a nonnormal distribution. Therefore, a nonparametric Mann-Whitney U-test was applied. Statistical differences for categorical variables were evaluated using the chi-squared test. The best-fit line was obtained by calculating the nonlinear regression (quadratic function) by plotting the SCC versus the normalized $\mathrm{OD}_{450}$ (added to a correction factor of 0.1). $\mathrm{R}^{2}$ was calculated as a parameter of goodness of fit by the software GraphPad Prism version 5.03 for Windows (GraphPad Software, La Jolla, CA). The descriptive statistical analysis (medians, interquartile ranges [IQR], and frequencies) was also carried out using GraphPad Prism. MedCalc Statistical Software version 15.2.2 (MedCalc Software bvba, Ostend, Belgium) was employed to generate receiver operating characteristic (ROC) curves and to calculate related values of area under the curve (AUC), Se, Sp, confidence intervals (CI), and the optimal cutoff values.

Latent class analysis (LCA) for calculation of Se, Sp, and $95 \%$ credible intervals $(\mathbf{C r I})$ was carried out with BayesianLatentClassModels (BLCM) V. 1.13 (http:// www.nandinidendukuri.com/blcm) (Dendukuri and Joseph, 2001; Dendukuri et al., 2009).

According to the latent class model, 3 assumptions need to be satisfied for method validation: the prevalence differs among the populations examined, Se and Sp are constant across subpopulations, and the tests are conditionally independent from each other. If the tests are not conditionally independent, the conditional dependence needs to be modeled.

The requirement for the difference in prevalence among the 3 examined populations was satisfied by using only the results from a sample subset, represented by flock $\mathrm{A}$, flock $\mathrm{B}$ at the first sampling, and flock $\mathrm{C}$ at the second sampling, for the LCA calculations. The subset data were as follows: flock $\mathrm{A}, \mathrm{n}=133$, prevalence $33.8 \%$; flock $\mathrm{B}, \mathrm{n}=136$, prevalence $14.0 \%$; and flock C: $\mathrm{n}=81$, prevalence $63.0 \%$. Prevalence was estimated by considering all samples having at least one positive result for ELISA with $\mathrm{OD}_{450}>0.014$, SCC $>500,000$ cells/mL, or bacteriological culture positivity as being positive.

The requirement for constant Se and Sp across flocks was satisfied by consecutively excluding each of the populations from the model. An overlap of the CrI of Se and Sp for ELISA with normalized $\mathrm{OD}_{450}>0.014$, SCC >500,000 and bacteriological culture positivity was observed in the 3 sample subsets used for LCA.

With regard to the requirement for conditional independence, because cathelicidin can be released by neutrophils as the main cell type, and neutrophils are also the main cell type found in mastitic milk (Smolenski et al., 2011; Addis et al., 2013; Pisanu et al., 2015), a conditional dependence of cathelicidin ELISA with SCC may exist. To account for this, we evaluated the dependence model between these 2 tests. According to the model diagnostics, the requirement for conditional independence was not satisfied. Therefore, the conditional dependence between cathelicidin and SCC was modeled. Uninformative priors, set as default parameters in the BLCM software, were used for cathelicidin ELISA and SCC because no reliable data were available in the current literature for these 2 parameters. For Se and Sp of bacteriological culture on a single milk sample, detailed and reliable estimates were available for cows (Dohoo et al., 2011). Therefore, the values of Se and Sp and their relative CI, reported by Dohoo et al. (2011) were used as priors, by considering condition E (defined in Dohoo et al., 2011), both for any organism and for CNS.

After definition of the parameters, Gibbs sampling was run. The first 500 iterations were discarded at the burn-in phase, and inferences were made based on the subsequent 10,000. Convergence of the Gibbs sampler 
algorithm was verified according to the trace plots for all runs.

\section{RESULTS}

\section{Bacteriological Culture Results}

All 705 milk samples were subjected to standard bacteriological culture, and $20.6 \%$ of them $(145 / 705)$ were positive. Coagulase-negative staphylococci were the most frequent finding $(74.5 \%, 108 / 145)$, followed by $E n$ terococcus faecalis, Lactococcus lactis, and Mannheimia haemolytica (4.1\%, 6/145, for each). Among the CNS, Staphylococcus epidermidis was by far the most frequent $(59.3 \%, 64 / 108)$.

\section{ROC Curve Analysis of Cathelicidin ELISA Results}

The presence of cathelicidin in ewe milk was evaluated by a pan-cathelicidin sandwich ELISA. The relationships of ELISA results with SCC and bacteriological culture were assessed by ROC curve analysis. As previously stated, values of SCC $<500,000$ or $>1,000,000$ cells $/ \mathrm{mL}$ should reliably indicate the absence or presence of mastitis, respectively (Berthelot et al., 2005; Fragkou et al., 2014; Gelasakis et al., 2015). Therefore, we plotted separate ROC curves for these 2 SCC thresholds. The curves are reported in Figure $1 \mathrm{~A}$ and $1 \mathrm{~B}$ for SCC >500,000 and for SCC >1,000,000 cells $/ \mathrm{mL}$, respectively. Figure 1C reports the ROC curve plotted against bacteriological culture results. The evaluation of cathelicidin ELISA against SCC produced very high AUC values for both SCC thresholds (Table 1). In the comparison of cathelicidin ELISA against bacteriological culture, the AUC was also high, but it was lower than both AUCs seen for SCC. ROC curve analysis also enabled defining optimal ELISA cutoff values; that is, those providing the best $\mathrm{Se} / \mathrm{Sp}$ trade-offs. At these optimal cutoff values, Se and Sp were very high for both SCC thresholds and bacteriological culture, although slightly lower in the latter case.

Of course, it should be highlighted that the Se/Sp trade-off can be balanced to the respective advantage of one or the other parameter when applying the test in practice by selecting different ELISA cutoff values. For evaluation of the test performances, in this work we used the optimal cutoff value of 0.014 as the threshold for defining cathelicidin ELISA-negative and cathelicidin-ELISA-positive samples.

\section{The Inflammation Marker Cathelicidin and SCC}

Out of 705 half-udder milk samples examined, 249 (35.3\%) were positive for cathelicidin according to the
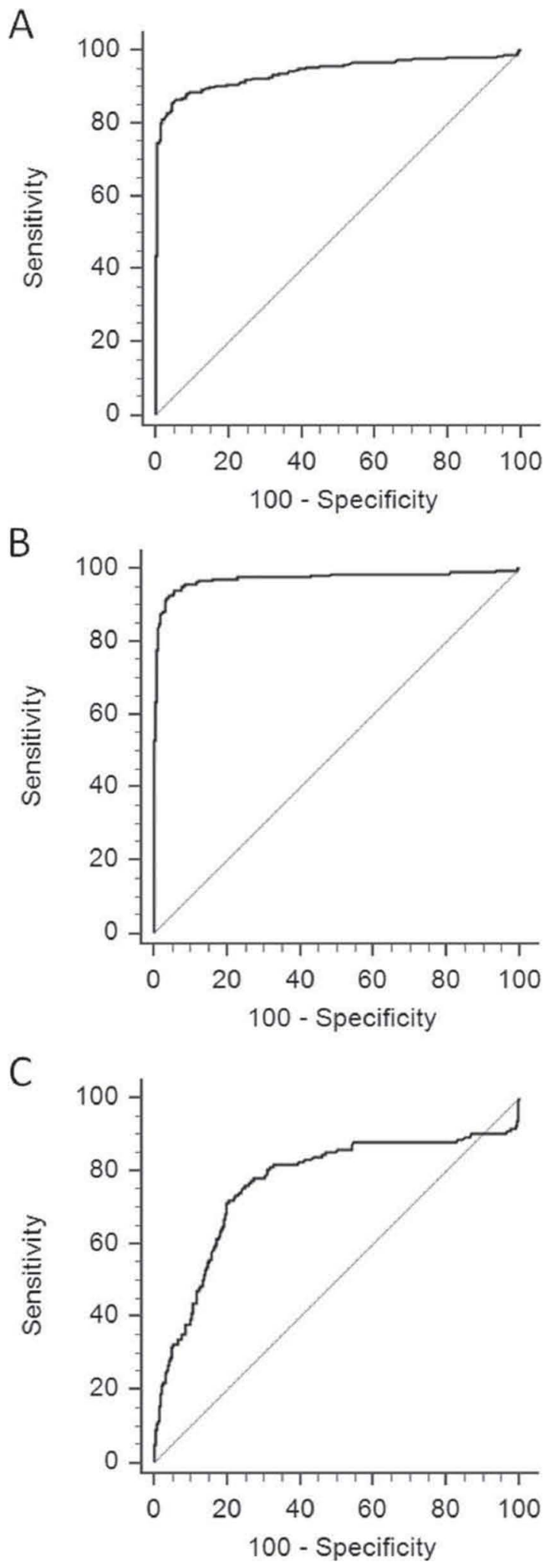

Figure 1. Receiver operating characteristic (ROC) curves illustrating the relationship of cathelicidin with SCC and bacteriological culture. (A) ROC curve plotted against SCC $>500,000$ cells $/ \mathrm{mL}$; (B) ROC curve plotted against SCC $>1,000,000$ cells/mL; (C) ROC curve plotted against bacteriological culture. 
Table 1. Area under the curve (AUC), selectivity (Se), specificity (Sp), and optimal ELISA cutoff values obtained by receiver operating characteristic (ROC) curve analysis when setting SCC or bacteriological culture results as the reference

\begin{tabular}{lcccc}
\hline Item & AUC $(95 \% \mathrm{CI})$ & $\begin{array}{c}\text { Optimal ELISA } \\
\text { cutoff value }^{1}\end{array}$ & \% Se (95\% CI) & \% Sp (95\% CI) \\
\hline $\mathrm{SCC}^{2}>500,000$ & $0.94(0.92-0.95)$ & 0.014 & $86.2(81.4-90.1)$ & $94.6(92.1-96.5)$ \\
$\mathrm{SCC}>1,000,000$ & $0.97(0.96-0.98)$ & 0.040 & $93.4(89.9-96.8)$ & $94.3(91.8-96.2)$ \\
Bacteriological culture & $0.76(0.73-0.79)$ & 0.039 & $71.1(62.9-78.4)$ & $80.1(76.6-83.3)$ \\
\hline
\end{tabular}

${ }^{1}$ ELISA in normalized optical density $(\mathrm{OD})_{450}$.

${ }^{2} \mathrm{SCC}$ in cells $/ \mathrm{mL}$.

optimal normalized $\mathrm{OD}_{450}$ cutoff value of 0.014 . For assessing the relationship between the amount of cathelicidin present in milk and the SCC, we plotted the normalized $\mathrm{OD}_{450}$ cathelicidin ELISA values against the SCC measured for each sample (Figure 2). We subsequently observed an increasing trend of $\mathrm{OD}_{450}$ values at increasing SCC (Spearman $\rho$ correlation 0.7335, $P$ $<0.0001)$. Therefore, a direct quantitative relationship existed between the abundance of cathelicidin in milk and the number of immune cells recruited in the udder upon exposure to a microbial stimulus.

The ELISA-negative and ELISA-positive samples showed a statistically significant separation $(P<$ 0.0001) according to SCC, as illustrated by the dot plot in Figure 3. SCC median (IQR) values of 149,500 $(98,250-265,300)$ and $3,300,000(1,225,000-13,831,000)$ cells/mL were observed, respectively.

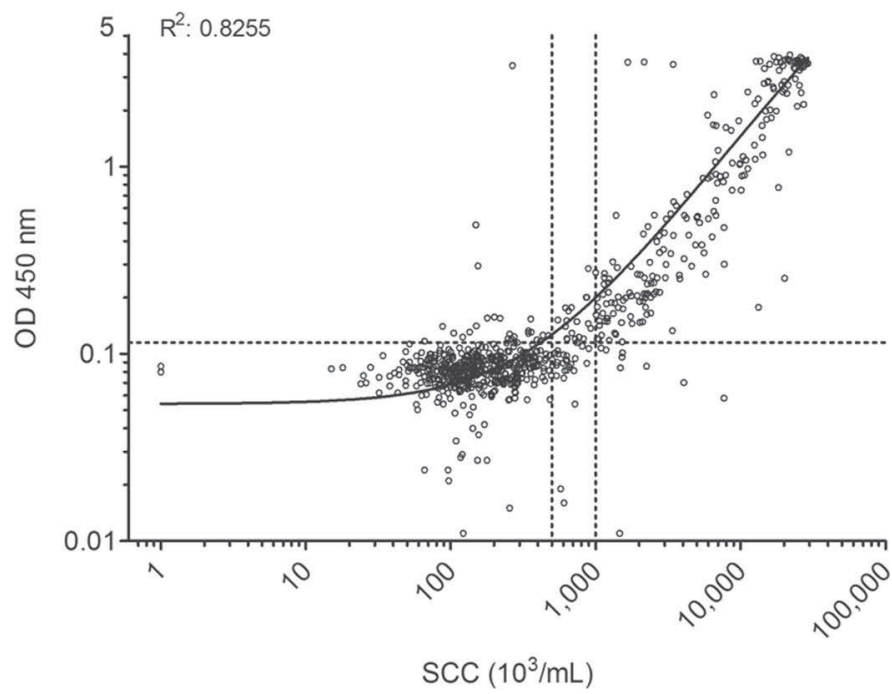

Figure 2. Distribution of cathelicidin positivity according to SCC values and normalized optical density $(\mathrm{OD})_{450}$. Dots indicate the value of all samples $(\mathrm{n}=705)$ along the trend line (quadratic function) plotted by increasing SCC and normalized $\mathrm{OD}_{450}$. A correction factor of 0.1 was applied to normalized $\mathrm{OD}_{450}$ values to enable an easier visualization in the plot. Horizontal dotted line $=$ ELISA cutoff value (normalized $\mathrm{OD}_{450} \geq 0.014$ ); vertical dotted lines $=\mathrm{SCC}$ thresholds of 500,000 and $1,000,000$ cells $/ \mathrm{mL}$

\section{Correlations Among Cathelicidin, Bacteriological Culture, and SCC}

To evaluate the distribution of cathelicidin and bacteriological culture results in relation to SCC, we grouped all samples into SCC classes according to Albenzio et al. (2012), as follows: class I, 1,000 to 300,000; class II, 301,000 to 500,000; class III, 501,000 to 1,000,000; class IV, 1,001,000 to 2,000,000; and class $\mathrm{V},>2,000,000$, to assess the absolute and relative frequency distribution (Figure 4A and 4B). As expected, cathelicidin positivity was mainly concentrated into classes with high SCC. However, cathelicidin positivity was also present in samples with low SCC, with $13.1 \%$ positivity in samples with $<500,000$ cells $/ \mathrm{mL}$ and $42.3 \%$ positivity in samples between 501,000 and 1,000,000 cells/mL. For bacteriological culture, the number of positive samples increased according to increasing SCC and cathelicidin positivity.

Table 2 reports the distribution of cathelicidin-negative and cathelicidin-positive samples according to the identified microorganism, within 3 SCC class groups;

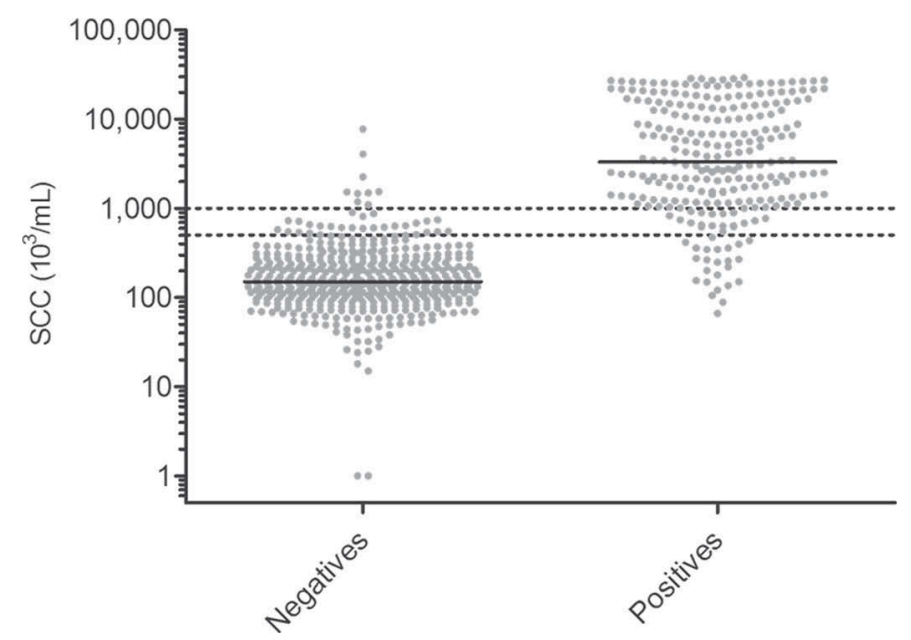

Figure 3. Dot plots indicating the distribution of SCC according to milk cathelicidin (negative or positive). The difference between negative and positive groups was statistically significant $(P<0.0001)$. Horizontal dotted lines indicate the SCC thresholds of 500,000 and $1,000,000$ cells $/ \mathrm{mL}$. 
namely, low, with $\mathrm{SCC} \leq 500,000$ cells $/ \mathrm{mL}$ (classes I and II); intermediate, with SCC between 500,000 and 1,000,000 (class III); and high, with SCC >1,000,000 (classes IV and V). In the low SCC group, 6.0\% (27/444) of samples were bacteriologically positive, and $18.5 \%$ $(5 / 27)$ of these were positive for cathelicidin. In the intermediate sample group, $37.0 \%(17 / 46)$ of samples were bacteriologically positive, and $41.2 \%(7 / 17)$ of them were positive for cathelicidin. In the high SCC class, $47.0 \%(101 / 215)$ of samples were bacteriologically positive, and $97.0 \%$ (98/101) of them were positive for cathelicidin. Next, CNS were evaluated separately as a result of being the most frequent finding and one of the main etiological agents of subclinical mastitis in ewes (Contreras et al., 2007; Souza et al., 2012). With the focus on CNS species only, $4.3 \%(19 / 444)$ of samples had a CNS positivity in the low SCC group, and $26.3 \%$ $(5 / 19)$ of them were positive for cathelicidin. In the

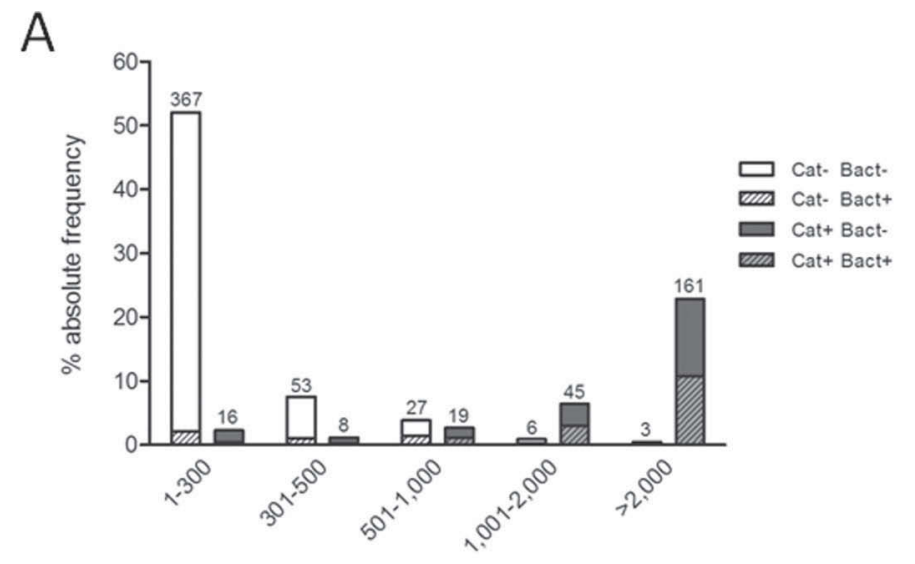

B

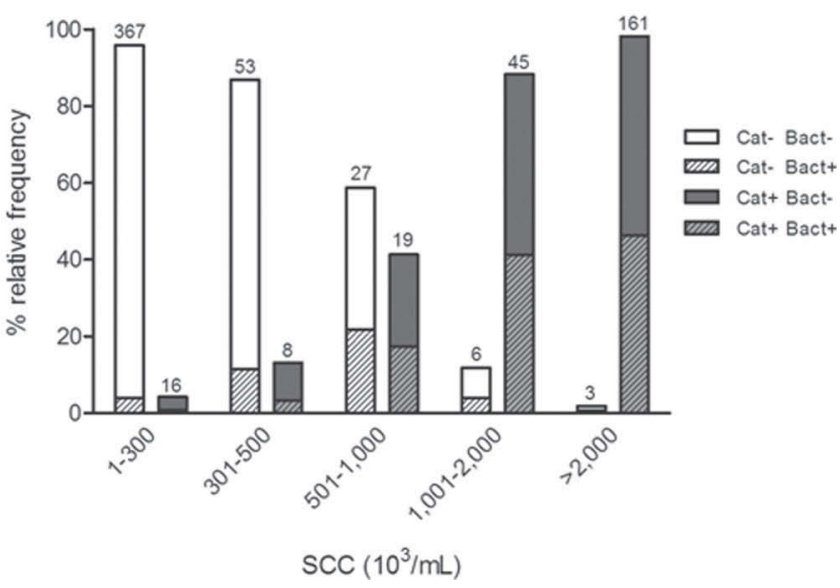

Figure 4. Frequency distribution of the cathelicidin (Cat) status according to SCC classes; $\mathrm{n}=705$; negative $=456$; positive $=249$. The number of samples within the class is reported above the bar. Shading indicates the relative proportion of bacteriologically (Bact + ) positive samples within the class. (A) Absolute SCC class distribution and (B) relative SCC class distribution, according to Albenzio et al. (2012). intermediate sample group, $26.1 \%(12 / 46)$ of samples had a CNS positivity, and $41.7 \%(5 / 12)$ of them were positive for cathelicidin. In the high SCC group, $35.9 \%$ (77/215) of samples had a CNS positivity, and $98.7 \%$ $(76 / 77)$ of them were positive for cathelicidin.

\section{Statistical Evaluation of Test Characteristics}

As previously stated, neither SCC nor bacteriological culture is a perfect mastitis test, so a serious bias might occur when estimating Se and Sp of cathelicidin with traditional approaches (Enøe et al., 2000). Therefore, LCA was carried out to evaluate the diagnostic performance of cathelicidin ELISA. In view of the close relationship of cathelicidin with SCC, conditional dependence between these 2 tests was modeled. As for the other test evaluations, LCA estimates were made by using $2 \mathrm{SCC}$ thresholds, $>500,000$ cells $/ \mathrm{mL}$ and $>1,000,000$ cells $/ \mathrm{mL}$. LCA estimates of Se and Sp were also calculated by considering only CNS. Table 3 shows the Se and Sp values obtained for cathelicidin, bacteriological culture, and SCC at the 2 thresholds.

\section{DISCUSSION}

Currently, a need exists for improving mastitis monitoring and detection in small ruminants because of the known limitations of SCC and the difficulties in the precise definition of the best diagnostic SCC threshold in ewes and in goats (Souza et al., 2012). This need is especially prominent with regard to the high prevalence of subclinical mastitis and of the significant problems encountered in its detection and control (Contreras et al., 2007; Souza et al., 2012). Therefore, novel methods providing an increase in Se without compromising Sp are to be sought. In addition, the identification of a reliable mastitis indicator, such as an inflammation marker, might also be useful for assessing, reinforcing, or integrating the SCC value in small ruminants. Cathelicidin emerged as a potentially reliable candidate in our previous studies carried out in ewes with natural and experimental infection with various mammary pathogens (Addis et al., 2011, 2013; Pisanu et al., 2015), and it is supported by studies from other authors in cows and in goats (Murakami et al., 2005; Ibeagha-Awemu et al., 2010; Tomasinsig et al., 2010; Smolenski et al., 2011; Brenaut et al., 2014). The value of cathelicidin resides in its well-known role in innate immunity of the mammary gland (Zanetti, 2004, 2005). In fact, it is released early, in a sensitive and specific manner, by epithelial cells and then by activated neutrophils recruited in the udder in response to a microbial stimulus, and it is therefore present in abundant amounts in mastitic milk (Addis et al., 2013; Pisanu et al., 2015). In the 
Table 2. Distribution of cathelicidin-negative (Cat-) and cathelicidin-positive (Cat+) samples according to the identified microorganism and to the SCC class

\begin{tabular}{|c|c|c|c|c|c|c|c|c|c|c|c|}
\hline Group & Bacterial species & Total & \multicolumn{3}{|c|}{ Low $\mathrm{SCC}^{1}$} & \multicolumn{3}{|c|}{ Intermediate $\mathrm{SCC}^{2}$} & \multicolumn{3}{|c|}{ High $\mathrm{SCC}^{3}$} \\
\hline \multirow{6}{*}{ CNS } & S. chromogenes & 12 & 2 & 2 & - & 1 & 1 & - & 9 & 1 & 8 \\
\hline & S. warneri & 6 & 2 & 1 & 1 & 2 & 2 & - & 2 & - & 2 \\
\hline & S. haemolyticus & 4 & - & - & - & - & - & - & 4 & - & 4 \\
\hline & S. auricularis & 2 & - & - & - & - & - & - & 2 & - & 2 \\
\hline & Other CNS & 17 & 3 & 1 & 2 & 1 & - & 1 & 13 & - & 13 \\
\hline & Total CNS & 108 & 19 & 14 & 5 & 12 & 7 & 5 & 77 & 1 & 76 \\
\hline \multirow[t]{5}{*}{ Other species } & Enterococcus faecalis & 6 & - & - & - & 1 & - & 1 & 5 & - & 5 \\
\hline & Lactococcus lactis & 6 & 3 & 3 & - & - & - & - & 3 & 1 & 2 \\
\hline & Mannheimia haemolytica & 6 & - & - & - & 1 & - & 1 & 5 & - & 5 \\
\hline & Streptococcus uberis & 3 & - & - & - & - & - & - & 3 & 1 & 2 \\
\hline & Staphylococcus aureus & 2 & - & - & - & 1 & 1 & - & 1 & - & 1 \\
\hline \multirow[t]{3}{*}{ Totals } & Positives & 145 & 27 & 22 & 5 & 17 & 10 & 7 & 101 & 3 & 98 \\
\hline & Negatives & 560 & 417 & 398 & 19 & 29 & 17 & 12 & 114 & 6 & 108 \\
\hline & All samples & 705 & 444 & 420 & 24 & 46 & 27 & 19 & 215 & 9 & 206 \\
\hline
\end{tabular}

${ }^{1} \mathrm{SCC}$ below 500,000 cells $/ \mathrm{mL}$.

${ }^{2} \mathrm{SCC}$ between 500,000 and 1,000,000 cells $/ \mathrm{mL}$.

${ }^{3} \mathrm{SCC}$ above $1,000,000$ cells $/ \mathrm{mL}$.

${ }^{4}$ Cathelicidin ELISA with normalized optical density $(\mathrm{OD})_{450}<0.014$.

${ }^{5}$ Cathelicidin ELISA with normalized $\mathrm{OD}_{450} \geq 0.014$

present study, we investigated the suitability of cathelicidin as a marker for improving detection of subclinical mastitis, and we compared results of these assessments with SCC and microbiological findings in half-udder milk samples. To this purpose, we implemented a pancathelicidin assay in an ELISA format for measurement of cathelicidin. The ELISA text has a wide range of advantages, being widespread and highly standardized, quantitative, and easily implemented in the laboratory workflow, even within low-budget infrastructures, without requiring dedicated or expensive instrumentation or advanced personnel training. In addition, it can be easily automated and carried out in multiplexing with extremely high throughputs.

We observed a very high correlation of cathelicidin with SCC, as demonstrated by (1) the results of the ROC curve analysis (Figure 1A and 1B), (2) the increase in milk cathelicidin abundance at increasing SCC (Figure 2), and (3) the clustering of cathelicidinnegative and cathelicidin-positive samples with low and high SCC, respectively (Figure 3). Nevertheless, some discrepancies were apparent, with several milk samples

Table 3. Mean and 95\% credible intervals (CrI) for selectivity (Se) and specificity (Sp) of cathelicidin. SCC at 2 cells/mL thresholds, and bacteriological culture $(\mathrm{BC})$, for the detection of mastitis according to the latent class analysis (LCA)

\begin{tabular}{|c|c|c|c|c|}
\hline \multirow[b]{2}{*}{ Item } & \multicolumn{2}{|c|}{$\mathrm{SCC}>500,000$ cells $/ \mathrm{mL}$} & \multicolumn{2}{|c|}{$\mathrm{SCC}>1,000,000$ cells $/ \mathrm{mL}$} \\
\hline & $\%$ Se $(95 \%$ CrI $)$ & \% Sp $(95 \% \mathrm{CrI})$ & $\%$ Se $(95 \% \mathrm{CrI})$ & $\%$ Sp $(95 \%$ CrI $)$ \\
\hline \multicolumn{5}{|l|}{ All pathogens } \\
\hline Cathelicidin ${ }^{1}$ & $92.3(79.9-99.1)$ & $92.3(86.6-97.0)$ & $93.3(81.8-99.1)$ & $91.9(85.9-97.2)$ \\
\hline $\mathrm{SCC}$ & $89.0(76.0-97.7)$ & $94.9(89.7-98.6)$ & $80.0(65.4-93.8)$ & $97.1(92.7-99.5)$ \\
\hline $\mathrm{BC}$ & $39.4(36.0-42.8)$ & $93.6(91.9-95.0)$ & $39.4(36.0-42.8)$ & $93.5(91.9-95.0)$ \\
\hline \multicolumn{5}{|c|}{$05.4(00.0+2.0)$} \\
\hline Cathelicidin & $91.1(77.1-98.9)$ & $92.1(86.1-96.9)$ & $91.2(77.6-98.9)$ & $91.8(85.7-97.0)$ \\
\hline SCC & $86.3(71.5-97.0)$ & $94.4(89.0-98.1)$ & $77.8(62.5-92.4)$ & $96.9(92.3-99.5)$ \\
\hline $\mathrm{BC}$ & $38.8(34.9-42.7)$ & $96.2(94.9-97.3)$ & $38.8(35.0-42.8)$ & $96.2(94.9-97.3)$ \\
\hline
\end{tabular}

${ }^{1}$ ELISA cutoff: normalized optical density $(\mathrm{OD})_{450} \geq 0.014$. 
being positive for cathelicidin without evident increases in the SCC. Specifically, the dot plots (Figure 3) clearly show that several cathelicidin-positive samples had very low SCC, and the distribution of cathelicidin positivity within SCC classes (Figure 4) highlights this finding. However, although most of the negative samples fall in class I $(<300,000$ cells $/ \mathrm{mL})$ and most of the positive samples fall in classes above IV $(>1,000,000$ cells/ $\mathrm{mL}$ ), a slight superimposition exists in class II (from 301,000 to 500,000 cells $/ \mathrm{mL}$ ), and an almost equivalent distribution is present in class III (from 501,000 to $1,000,000$ cells $/ \mathrm{mL}$ ). In milk samples falling in SCC classes II and III, therefore, the measurement of cathelicidin might provide significant benefits in terms of increased subclinical mastitis detection by revealing the presence of otherwise undetected inflammatory events. This possibility suggests that, in cases in which the individual half-udder milk sample has a SCC between 300,000 and $1,000,000$ cells $/ \mathrm{mL}$ and cathelicidin is positive, a treatment or intervention decision may be undertaken or bacteriology done to define the etiology of the inflammation. If cathelicidin is negative, then a SCC false positive would be likely, and an unnecessary bacteriological culture, treatment, or culling would be avoided. In fact, several non-IMI causes are known to cause transient SCC increases in sheep without a concurrent release of inflammation markers (Berthelot et al., 2006; Souza et al., 2012), and residual, spent somatic cells may still be found in milk after an inflammation stimulus has ceased. However, further investigations would be advised to better dissect the modes and kinetics of cathelicidin release in milk as well as its relationships with the specific IMI agent. In fact, we cannot rule out that samples with high SCC that are negative for cathelicidin might reflect a short half-life of cathelicidin or some bias in the measurement assay.

All these observations also highlight that, as already known, neither SCC nor bacteriological culture represents a reliable gold standard for evaluating the diagnostic performance of a novel diagnostic test such as the cathelicidin ELISA because their respective biases could lead to significant errors in estimating the Se and Sp of the new test (Enøe et al., 2000). An option that enables circumventing this issue is represented by the LCA approach (Hui and Walter, 1980), which is based on a probabilistic cross-classification of results and provides a better estimate of Se and Sp of a novel diagnostic test in the absence of a true gold standard (Georgiadis et al., 2003). Latent class analysis is increasingly being implemented in the evaluation of methods for detecting mastitis and IMI (Dohoo et al., 2011; Koop et al., 2011; Fosgate et al., 2013; Vissio et al., 2014) For the latent class model to be applicable, 3 assumptions need to be satisfied: the prevalence differs among the populations examined, Se and Sp are constant across subpopulations, and the tests are conditionally independent from each other. Conditional independence among tests implies that when the disease status of a test subject is known, the probability of a test result is unaffected by the outcome of another test (Dawid, 1979; Toft et al., 2005). If the tests are not conditionally independent, conditional dependence needs to be modeled. In this work, the results clearly indicated that cathelicidin and SCC are strongly related. Therefore, LCA was applied by taking into account the conditional dependence of cathelicidin and SCC.

As a result, cathelicidin always showed a superior Se compared with SCC. In addition, Sp of cathelicidin was also high, especially in the comparison with SCC $>500,000$ cells $/ \mathrm{mL}$ (Table 3 ). This finding is especially relevant because it may provide significant advantages in the detection of subclinical mastitis. As expected, Se of bacteriological culture was always the lowest. Notably, Sp of cathelicidin and SCC was very close to Sp of bacteriological culture, and both cathelicidin and SCC outperformed bacteriological culture when 1,000,000 cells/mL was the diagnostic SCC threshold.

Although LCA compensates for the absence of a gold standard test, cathelicidin Sp might still be slightly underestimated. In fact, because cathelicidin has a higher Se than SCC and bacteriological culture, several samples will produce a positive result for cathelicidin and negative results for both SCC and bacteriological culture. These results will be classified as false positives, but they may actually be false negatives of the other 2, less sensitive, tests. Further studies may be needed to better define the ELISA cathelicidin Sp, which might be even higher than the one observed upon LCA against SCC and bacteriological culture.

The performance of cathelicidin as a mastitis marker, its proteinaceous nature, and its strict correlation with inflammation (Frohm et al., 1997; Zanetti, 2004, 2005; Smolenski et al., 2007; Nijnik and Hancock, 2009; Addis et al., 2013) support the implementation of other immunoassay platforms for its detection. In most cases, the availability of quality antibodies is a limiting factor in developing sensitive, specific, and reproducible laboratory or field immunoassay tests (Baker, 2015; Bradbury and Plückthun, 2015). Here, the availability of specific monoclonal antibodies against a pan-cathelicidin domain opens the way to its exploitation in a wide range of immunoassay formats enabling pen-side and on-line measurement of the marker.

As a final consideration, in view of the nature of the cathelicidin marker and its involvement in innate immunity processes, the possible implementation in other dairy ruminants, such as cows, goats, or water buffaloes, seems to represent a tangible perspective. Particularly 
in the case of goats, for which the SCC problem is well known and has an even greater impact than in sheep, the possible applicability of this marker for mastitis detection deserves further investigation.

\section{ACKNOWLEDGMENTS}

We thank Paolo Moroni for the insightful discussions on dairy animal mastitis and intramammary infections, and for his suggestions on the manuscript. We also thank Ignazio Ibba and Marino Contu of the Regional Farmer's Association of Sardinia (ARA Sardegna) for insights on sheep mastitis and SCC. Alessandro Guaraglia is gratefully acknowledged for support with implementation of the LCA tools. This work was supported by Regione Autonoma della Sardegna with funds granted to the Sardinia Regional Science and Technology Park.

\section{REFERENCES}

Addis, M. F., S. Pisanu, S. Ghisaura, D. Pagnozzi, G. Marogna, A. Tanca, G. Biosa, C. Cacciotto, A. Alberti, M. Pittau, T. Roggio, and S. Uzzau. 2011. Proteomics and pathway analyses of the milk fat globule in sheep naturally infected by Mycoplasma agalactiae provide indications of the in vivo response of the mammary epithelium to bacterial infection. Infect. Immun. 79:3833-3845. http:// dx.doi.org/10.1128/IAI.00040-11.

Addis, M. F., S. Pisanu, G. Marogna, T. Cubeddu, D. Pagnozzi, C. Cacciotto, F. Campesi, G. Schianchi, S. Rocca, and S. Uzzau. 2013. Production and release of antimicrobial and immune defense proteins by mammary epithelial cells following Streptococcus uberis infection of sheep. Infect. Immun. 81:3182-3197. http://dx.doi. org/10.1128/IAI.00291-13.

Akerstedt, M., L. Forsbäck, T. Larsen, and K. Svennersten-Sjaunja. 2011. Natural variation in biomarkers indicating mastitis in healthy cows. J. Dairy Res. 78:88-96. http://dx.doi.org/10.1017/ S0022029910000786.

Albenzio, M., A. Santillo, M. Caroprese, D. Ruggieri, M. Ciliberti, and A. Sevi. 2012. Immune competence of the mammary gland as affected by somatic cell and pathogenic bacteria in ewes with subclinical mastitis. J. Dairy Sci. 95:3877-3887. http://dx.doi. org/10.3168/jds.2012-5357.

Baker, M. 2015. Reproducibility crisis: Blame it on the antibodies. Nature 521:274-276. http://dx.doi.org/10.1038/521274a.

Bergonier, D., R. De Crémoux, R. Rupp, G. Lagriffoul, and X. Berthelot. 2003. Mastitis of dairy small ruminants. Vet. Res. 34:689-716. http://dx.doi.org/10.1051/vetres:2003030.

Berthelot, X., G. Lagriffoul, D. Concordet, F. Barillet, and D. Bergonier. 2005. Physiological and pathological thresholds of somatic cell counts in ewe milk. Pages 40-43 in Proc. 6th Int. Sheep Vet. Congr., Hersonissos, Greece. Hellenic Veterinary Medical Society, Thessaloniki, Greece.

Berthelot, X., G. Lagriffoul, D. Concordet, F. Barillet, and D. Bergonier. 2006. Physiological and pathological thresholds of somatic cell counts in ewe milk. Small Rumin. Res. 62:27-31. http:// dx.doi.org/10.1016/j.smallrumres.2005.07.047.

Boehmer, J. L., J. A. DeGrasse, M. A. McFarland, E. A. Tall, K. J. Shefcheck, J. L. Ward, and D. D. Bannerman. 2010. The proteomic advantage: Label-free quantification of proteins expressed in bovine milk during experimentally induced coliform mastitis. Vet. Immunol. Immunopathol. 138:252-266. http://dx.doi. org $/ 10.1016 /$ j.vetimm.2010.10.004.

Bradbury, A., and A. Plückthun. 2015. Reproducibility: Standardize antibodies used in research. Nature 518:27-29. http://dx.doi. org/10.1038/518027a.
Brenaut, P., L. Lefèvre, A. Rau, D. Laloë, G. Pisoni, P. Moroni, C. Bevilacqua, and P. Martin. 2014. Contribution of mammary epithelial cells to the immune response during early stages of a bacterial infection to Staphylococcus aureus. Vet. Res. 45:16. http:// dx.doi.org/10.1186/1297-9716-45-16.

Ceciliani, F., J. J. Ceron, P. D. Eckersall, and H. Sauerwein. 2012. Acute phase proteins in ruminants. J. Proteomics 75:4207-4231. http://dx.doi.org/10.1016/j.jprot.2012.04.004.

Chromek, M., Z. Slamová, P. Bergman, L. Kovács, L. Podracká, I. Ehrén, T. Hökfelt, G. H. Gudmundsson, R. L. Gallo, B. Agerberth, and A. Brauner. 2006. The antimicrobial peptide cathelicidin protects the urinary tract against invasive bacterial infection. Nat. Med. 12:636-641. http://dx.doi.org/10.1038/nm1407.

Contreras, A., D. Sierra, A. Sánchez, J. C. Corrales, J. C. Marco, M. J. Paape, and C. Gonzalo. 2007. Mastitis in small ruminants. Small Rumin. Res. 68:145-153. http://dx.doi.org/10.1016/j. smallrumres.2006.09.011.

Danowski, K., J. J. Gross, H. H. D. Meyer, and H. Kliem. 2013. Effects of induced energy deficiency on lactoferrin concentration in milk and the lactoferrin reaction of primary bovine mammary epithelial cells in vitro. J. Anim. Physiol. Anim. Nutr. (Berl.) 97:647-655. http://dx.doi.org/10.1111/j.1439-0396.2012.01305.x.

Dawid, A. P. 1979. Conditional independence in statistical theory. J. R. Stat. Soc., B 41:1-31.

Dendukuri, N., A. Hadgu, and L. Wang. 2009. Modeling conditional dependence between diagnostic tests: A multiple latent variable model. Stat. Med. 28:441-461. http://dx.doi.org/10.1002/ sim. 3470 .

Dendukuri, N., and L. Joseph. 2001. Bayesian approaches to modeling the conditional dependence between multiple diagnostic tests. Biometrics 57:158-167.

Dohoo, I. R., J. Smith, S. Andersen, D. F. Kelton, and S. Godden. 2011. Diagnosing intramammary infections: Evaluation of definitions based on a single milk sample. J. Dairy Sci. 94:250-261. http://dx.doi.org/10.3168/jds.2010-3559.

Enøe, C., M. P. Georgiadis, and W. O. Johnson. 2000. Estimation of sensitivity and specificity of diagnostic tests and disease prevalence when the true disease state is unknown. Prev. Vet. Med. 45:61-81. http://dx.doi.org/10.1016/S0167-5877(00)00117-3.

Fosgate, G. T., I. M. Petzer, and J. Karzis. 2013. Sensitivity and specificity of a hand-held milk electrical conductivity meter compared to the California mastitis test for mastitis in dairy cattle. Vet. J. 196:98-102. http://dx.doi.org/10.1016/j.tvjl.2012.07.026.

Fragkou, I. A., C. M. Boscos, and G. C. Fthenakis. 2014. Diagnosis of clinical or subclinical mastitis in ewes. Small Rumin. Res. 118:8692. http://dx.doi.org/10.1016/j.smallrumres.2013.12.015.

Frohm, M., B. Agerberth, G. Ahangari, M. Stâhle-Bäckdahl, S. Lidén, H. Wigzell, and G. H. Gudmundsson. 1997. The expression of the gene coding for the antibacterial peptide LL-37 is induced in human keratinocytes during inflammatory disorders. J. Biol. Chem. 272:15258-15263.

Gelasakis, A. I., V. S. Mavrogianni, I. G. Petridis, N. G. C. Vasileiou, and G. C. Fthenakis. 2015. Mastitis in sheep-The last 10 years and the future of research. Vet. Microbiol. http://dx.doi. org/10.1016/j.vetmic.2015.07.009.

Georgiadis, M. P., W. O. Johnson, I. A. Gardner, and R. Singh. 2003. Correlation-adjusted estimation of sensitivity and specificity of two diagnostic tests. J. R. Stat. Soc. Ser. C. Appl. Stat. 52:63-76. http://dx.doi.org/10.1111/1467-9876.00389.

Gurjar, A., G. Gioia, Y. Schukken, F. Welcome, R. Zadoks, and P. Moroni. 2012. Molecular diagnostics applied to mastitis problems on dairy farms. Vet. Clin. North Am. Food Anim. Pract. 28:565-576. http://dx.doi.org/10.1016/j.cvfa.2012.07.011.

Hui, S. L., and S. D. Walter. 1980. Estimating the error rates of diagnostic tests. Biometrics 36:167-171.

Ibeagha-Awemu, E. M., A. E. Ibeagha, S. Messier, and X. Zhao. 2010. Proteomics, genomics, and pathway analyses of Escherichia coli and Staphylococcus aureus infected milk whey reveal molecular pathways and networks involved in mastitis. J. Proteome Res. 9:4604-4619. http://dx.doi.org/10.1021/pr100336e. 
ISO. 2006. ISO 13366-2:2006. Milk-Enumeration of somatic cellsPart 2: Guidance on the operation of fluoro-opto-electronic counters. International Organization for Standardization (ISO), Geneva, Switzerland.

Koop, G., T. van Werven, N. Toft, and M. Nielen. 2011. Estimating test characteristics of somatic cell count to detect Staphylococcus aureus-infected dairy goats using latent class analysis. J. Dairy Sci. 94:2902-2911. http://dx.doi.org/10.3168/jds.2010-3929.

Kościuczuk, E. M., P. Lisowski, J. Jarczak, N. Strzałkowska, A. Jóźwik, J. Horbańczuk, J. Krzyżewski, L. Zwierzchowski, and E. Bagnicka. 2012. Cathelicidins: Family of antimicrobial peptides. A review. Mol. Biol. Rep. 39:10957-10970. http://dx.doi.org/10.1007/ s11033-012-1997-x.

Lippolis, J.D., T. A. Reinhardt, J. P. Goff, and R. L. Horst. 2006. Neutrophil extracellular trap formation by bovine neutrophils is not inhibited by milk. Vet. Immunol. Immunopathol. 113:248-255. http://dx.doi.org/10.1016/j.vetimm.2006.05.004.

Maddau, L., A. Cabras, A. Franceschini, B. T. Linaldeddu, S. Crobu, T. Roggio, and D. Pagnozzi. 2009. Occurrence and characterization of peptaibols from Trichoderma citrinoviride, an endophytic fungus of cork oak, using electrospray ionization quadrupole timeof-flight mass spectrometry. Microbiology 155:3371-3381. http:// dx.doi.org/10.1099/mic.0.030916-0.

Marogna, G., S. Rolesu, S. Lollai, S. Tola, and G. Leori. 2010. Clinical findings in sheep farms affected by recurrent bacterial mastitis. Small Rumin. Res. 88:119-125. http://dx.doi.org/10.1016/j. smallrumres.2009.12.019.

McDougall, S., P. Murdough, W. Pankey, C. Delaney, J. Barlow, and D. Scruton. 2001. Relationships among somatic cell count, California mastitis test, impedance and bacteriological status of milk in goats and sheep in early lactation. Small Rumin. Res. 40:245-254.

Merrifield, R. B. 1963. Solid phase peptide synthesis. I. The synthesis of a tetrapeptide. J. Am. Chem. Soc. 85:2149-2154. http://dx.doi. org/10.1021/ja00897a025.

Miglio, A., L. Moscati, G. Fruganti, M. Pela, E. Scoccia, A. Valiani, and C. Maresca. 2013. Use of milk amyloid A in the diagnosis of subclinical mastitis in dairy ewes. J. Dairy Res. 80:496-502. http://dx.doi.org/10.1017/S0022029913000484.

Mura, S., G. Greppi, A. M. Roggio, L. Malfatti, and P. Innocenzi 2011. Polypeptide binding to mesostructured titania films. Microporous Mesoporous Mater. 142:1-6. http://dx.doi.org/10.1016/j. micromeso.2010.10.047.

Murakami, M., R. A. Dorschner, L. J. Stern, K. H. Lin, and R. L. Gallo. 2005. Expression and secretion of cathelicidin antimicrobial peptides in murine mammary glands and human milk. Pediatr. Res. 57:10-15. http://dx.doi.org/10.1203/01. PDR.0000148068.32201.50.

Nijnik, A., and R. Hancock. 2009. Host defence peptides: Antimicrobial and immunomodulatory activity and potential applications for tackling antibiotic-resistant infections. Emerg. Health Threats J. 2:e1 http://dx.doi.org/10.3134/ehtj.09.001.

Pisanu, S., T. Cubeddu, D. Pagnozzi, S. Rocca, C. Cacciotto, A. Alberti, G. Marogna, S. Uzzau, and M. F. Addis. 2015. Neutrophil extracellular traps in sheep mastitis. Vet. Res. 46:59 http://dx.doi. org/10.1186/s13567-015-0196-x.

Plumed-Ferrer, C., K. Uusikylä, J. Korhonen, and A. von Wright, 2013. Characterization of Lactococcus lactis isolates from bovine mastitis. Vet. Microbiol. 167:592-599. http://dx.doi.org/10.1016/j. vetmic.2013.09.011.

Rainard, P., and C. Riollet. 2006. Innate immunity of the bovine mammary gland. Vet. Res. 37:369-400. http://dx.doi.org/10.1051/ vetres:2006007.

Reinhardt, T. A., R. E. Sacco, B. J. Nonnecke, and J. D. Lippolis. 2013. Bovine milk proteome: Quantitative changes in normal milk exosomes, milk fat globule membranes and whey proteomes resulting from Staphylococcus aureus mastitis. J. Proteomics 82:141-154. http://dx.doi.org/10.1016/j.jprot.2013.02.013.

Saad, A. M., and K. Ostensson. 1990. Flow cytofluorometric studies on the alteration of leukocyte populations in blood and milk during endotoxin-induced mastitis in cows. Am. J. Vet. Res. 51:16031607.
Scumaci, D., F. Trimboli, L. Dell'Aquila, A. Concolino, G. Pappaianni, L. Tammè, G. Vignola, A. Luciani, D. Morelli, G. Cuda, A. Boari, and D. Britti. 2015. Proteomics-driven analysis of ovine whey colostrum. PLoS One 10:e0117433 http://dx.doi.org/10.1371/ journal.pone.0117433.

Sladek, Z., D. Rysanek, H. Ryznarova, and M. Faldyna. 2005. Neutrophil apoptosis during experimentally induced Staphylococcus aureus mastitis. Vet. Res. 36:629-643. http://dx.doi.org/10.1051/ vetres: 2005023

Smolenski, G., S. Haines, F. Y. S. Kwan, J. Bond, V. Farr, S. R. Davis, K. Stelwagen, and T. T. Wheeler. 2007. Characterisation of host defense proteins in milk using a proteomic approach. J. Proteome Res. 6:207-215.

Smolenski, G. A., R. J. Wieliczko, S. M. Pryor, M. K. Broadhurst, T. T. Wheeler, and B. J. Haigh. 2011. The abundance of milk cathelicidin proteins during bovine mastitis. Vet. Immunol. Immunopathol 143:125-130. http://dx.doi.org/10.1016/j.vetimm.2011.06.034.

Souza, F. N., M. G. Blagitz, C. F. A. M. Penna, A. M. M. P. Della Libera, M. B. Heinemann, and M. M. O. P. Cerqueira. 2012. Somatic cell count in small ruminants: Friend or foe? Small Rumin. Res. 107:65-75. http://dx.doi.org/10.1016/j.smallrumres.2012.04.005.

Toft, N., E. Jorgensen, and S. Hojsgaard. 2005. Diagnosing diagnostic tests: Evaluating the assumptions underlying the estimation of sensitivity and specificity in the absence of a gold standard. Prev. Vet. Med. 68:19-33. http://dx.doi.org/10.1016/j. prevetmed.2005.01.006.

Tomasinsig, L., G. De Conti, B. Skerlavaj, R. Piccinini, M. Mazzilli, F. D'Este, A. Tossi, and M. Zanetti. 2010. Broad-spectrum activity against bacterial mastitis pathogens and activation of mammary epithelial cells support a protective role of neutrophil cathelicidins in bovine mastitis. Infect. Immun. 78:1781-1788. http://dx.doi. org/10.1128/IAI.01090-09.

Trend, S., T. Strunk, J. Hibbert, C. H. Kok, G. Zhang, D. a. Doherty, P. Richmond, D. Burgner, K. Simmer, D. J. Davidson, and A. J. Currie. 2015. Antimicrobial protein and peptide concentrations and activity in human breast milk consumed by preterm infants at risk of late-onset neonatal sepsis. PLoS One 10:e0117038. http:// dx.doi.org/10.1371/journal.pone.0117038.

Viguier, C., S. Arora, N. Gilmartin, K. Welbeck, and R. O'Kennedy. 2009. Mastitis detection: Current trends and future perspectives. Trends Biotechnol. 27:486-493. http://dx.doi.org/10.1016/j. tibtech.2009.05.004.

Vissio, C., S. A. Dieser, H. L. Agnelli, L. M. Odierno, and A. J. Larriestra. 2014. Accuracy of the composite somatic cell count to detect intra-mammary infection in dairy cows using latent class analysis. Prev. Vet. Med. 113:547-555. http://dx.doi. org/10.1016/j.prevetmed.2013.11.016.

Walker, J. B., P. J. Rajala-Schultz, W. L. Walker, J. L. Mathews, W A. Gebreyes, and F. J. DeGraves. 2011. Variation in daily shedding patterns of Staphylococcus aureus in naturally occurring intramammary infections. J. Vet. Diagn. Invest. 23:1114-1122. http:// dx.doi.org/10.1177/1040638711425587.

Watts, J. L. 1990. Bovine mastitis. Pages 469-478 in Diagnostic Procedures in Veterinary Bacteriology and Mycology. 5th ed. G. R. Carter and J. R. J. Cole, ed. San Diego, CA.

Wheeler, T. T., G. A. Smolenski, D. P. Harris, S. K. Gupta, B. J Haigh, M. K. Broadhurst, A. J. Molenaar, and K. Stelwagen. 2012. Host-defence-related proteins in cows' milk. Animal 6:415-422. http://dx.doi.org/10.1017/S1751731111002151.

Wiesner, J., and A. Vilcinskas. 2010. Antimicrobial peptides-The ancient arm of the human immune system. Virulence 1:440-464.

Zanetti, M. 2004. Cathelicidins, multifunctional peptides of the innate immunity. J. Leukoc. Biol. 75:39-48. http://dx.doi.org/10.1189/ jlb.0403147.

Zanetti, M. 2005. The role of cathelicidins in the innate host defenses of mammals. Curr. Issues Mol. Biol. 7:179-196.

Zanetti, M., L. Litteri, G. Griffiths, R. Gennaro, and D. Romeo. 1991 Stimulus-induced maturation of probactenecins, precursors of neutrophil antimicrobial polypeptides. J. Immunol. 146:4295-4300. 